\title{
Tense and Intensionality in Specificational Copular Sentences
}

\author{
Maribel Romero \\ University of Pennsylvania
}

\section{Introduction}

Copular sentences of the shape XP1 is XP2 can be divided into at least two types: predicational, where XP2 predicates a property of XP1, as in (1); and specificational, where XP2 intuitively identifies the value of XP1, as in (2).

(1) The number of planets is large.

(2) The number of planets is nine.
PREDICATIONAL

SPECIFICATIONAL

Specificational sentences show Connectivity Effects (Akmajian 1970, Higgins 1979, Halvorsen 1978, Jacobson 1994, among others). For example, an NP like no man embedded in a relative clause in general cannot bind a pronoun outside the relative clause, as illustrated in (3a); but in specificational copular sentences this binding is possible, as in (3b). This effect is called Variable Binding Connectivity. Similarly, the NP a unicorn cannot be interpreted de dicto with respect to the embedded verb look for in (4a); but a de dicto reading is possible in the specificational sentence (4b) (Opacity Connectivity). Connectivity will be used in this paper as a diagnosis for specificational sentences.

(3) a. Predicational: $*$ The woman no $\operatorname{man}_{1}$ danced with last night was interested in $\operatorname{him}_{1}$.

b. Specificational: The woman no $\operatorname{man}_{1}$ hates is his ${ }_{1}$ mother.

(4) a. Predicational: What John is looking for is next to a unicorn.

b. Specificational: What John is looking for is a unicorn.

Specificational sentences further exhibit a tense restriction known as "Tense Harmony": they cannot at the same time have present tense inside XP1 and past tense in matrix be, as schematized in (5) (Sharvit 2003; see also Akmajian 1970, Higgins 1979). Predicational sentences do not observe this restriction. This is illustrated by the contrast in (6)-(7).

(5) Tense Harmony pattern:
a. [XP1 ...PAST...] PAST
b. [XP1 ...PRES...] PRES 
c. [XP1 ...PAST...] PRES (acceptable in special contexts)

d. * $[\mathrm{XP1}$...PRES...] PAST

(6) Predicational:

(Sharvit 2003)

a. [What John once read] was (once) interesting.

b. [What John reads when he comes home] is interesting.

c. [What John once read] is interesting.

d. [What John reads when he comes home] was (once) interesting.

(7) Specificational:

(Sharvit 2003)
a. [What John was] was a fool.
b. [What John is] is a fool.
c. [What John was] is a fool.
d. * [What John $\underline{\text { is] }}$ was a fool.

Sharvit (2003) derives Tense Harmony from the idea that, in the formula corresponding to the entire sentence, the matrix tense operator must bind a tense variable within XP1. For example, in (8a) and its semantic representation (8b), the $\exists t$ introduced by matrix PAST must bind the tense variable $t$ in $x x[\operatorname{president}(x, t)]$.
a. The president was Bill Clinton.
b. $\exists \mathrm{t}[\mathrm{t}<$ now $\wedge \mathrm{tx}[$ president $(\mathrm{x}, \mathrm{t})]=\mathrm{bc}]$

This idea can be implemented in two ways. Strategy I assumes a L(ogical) F(orm) where matrix $P A S T$ directly binds the temporal variable in XP1 and where

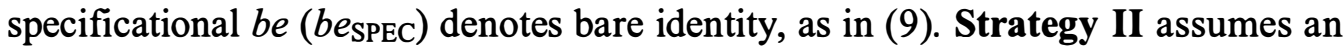
LF where the temporal variable in XP1 is bound within the XP1 itself and treats be $e_{\mathrm{SPEC}}$ as (temporally) intensional, as in (10). As the two strategies lead to the same result in her examples, Sharvit leaves the choice between the two open. ${ }^{1}$
a. PAST 1 [ [the president- $t_{1}$ ] be Bill Clinton ]
b. $\llbracket b e \rrbracket^{\mathrm{g}}=\lambda \mathrm{X}_{\sigma} \lambda \mathrm{Y}_{\sigma} . \mathrm{Y}=\mathrm{X}$
a. PAST 1 [ [ 2 the president- $\mathrm{t}_{2}$ ] be- $\mathrm{t}_{1}$ Bill Clinton ]
b. $\llbracket b e \rrbracket^{\mathrm{g}}=\lambda \mathrm{t}_{\mathrm{i}} \lambda \mathrm{X}_{\sigma} \lambda \mathrm{Y}_{<\mathrm{i}, \sigma>} . \mathrm{Y}(\mathrm{t})=\mathrm{X}$

The goal of this paper is to argue for strategy II. First, in section 2, I will show that the two strategies must in general be distinguished, since they lead to different empirical results in other constructions. Second, once this distinction is made, section 3 will present data in support of strategy II over strategy I for specificational sentences. To this end, an analysis of know with Concealed Question NPs will be presented in section 3.1 and extended to be $e_{\text {SPCC }}$ in section 3.2 , concluding that $b e_{\mathrm{SPEC}}$ is an intensional verb. Third and finally, section 4 will recast Sharvit's (2003) analysis of Tense Harmony within strategy II. 


\section{Temporal dependence vs. (world and temporal) intensionality}

On the one hand, building on Enç (1981, 1986), Musan (1995) argues that NPs with cardinal readings -e.g., bare plurals with an $\exists$-interpretation- have only a temporal dependent reading in German, as the contrast between (11) and (12) shows. The same holds for Spanish bare plurals, witness (13)-(14). These temporally dependent readings can be captured by requiring an LF where the local tense operator binds a variable inside the bare plural NP, in the spirit of strategy I.

(11) Die meisten Professoren waren in den sechziger glücklich.

The most professors were in the sixties happy

'Most professors were happy in the sixties.'

a. Temporally dependent: 'The majority of individuals that were professors in the 60s were happy in the 60s.'

b. Temporally independent: 'The majority of individuals that are professors now were happy in the 60s.'

(12) In den sechziger Jahren waren ja doch Professoren glücklich.

In the sixties were (indeed) professors happy

'In the sixties, [some] professors were (indeed) happy.'

a. Temporally dependent.

b. * Temporally independent.

(13) Juan conoció a la mayoría de los profesores en 1985.

Juan met A the majority of the professors in 1985.

'Juan met most professors in 1985.'

a. Temporally dependent.

b. Temporally independent.

(14) Juan conoció a profesores en 1985.

Juan met A professors in 1985.

'Juan met professors in 1985.'

a. Temporally dependent.

b. * Temporally independent.

On the other hand, when an NP with a relative clause (RC) functions as the object of an intensional verb like buscar 'look for' in Spanish, the mood in the RC encodes the scopal relation between the two (see Farkas 1993, Quer 1998): Indicative mood signals that the NP is interpreted de re, and Subjunctive signals that the NP is taken de dicto. This generalization is sketched in (15) and illustrated 
in (16)-(17). De dicto readings follow from the fact that look for takes as its semantic argument the intension of the NP, in a way parallel to strategy II.

$$
\begin{aligned}
& \text { buscar 'look for' }+ \text { [NP ... [RC ...INDICATIVE...] }] \Rightarrow \text { NP de re } \\
& \text { buscar 'look for' }+[\mathrm{NP} \ldots \text { [RC ...SUBJUNCTIVE...] }] \Rightarrow \text { NP de dicto }
\end{aligned}
$$

(16) En 1990, Juan estaba buscando a un profesor que podía hablar 7 idiomas. In 1990 J. was looking-for A a professor that could-IND speak 7 lgs 'In 1990, Juan was looking for a professor that could-IND speak 7 languages.'

NP de re

(17) En 1990, Juan estaba buscando a un profesor que pudiese hablar 7 idiomas In 1990 J. was looking-for A a professor that could-SUBJ speak 7 lgs 'In 1990, Juan was looking for a professor that could-SUBJ speaks 7 languages.'

NP de dicto

The question then arises whether, empirically, temporal dependence and (world/temporal) intensionality are the same phenomenon. This can be determined by answering the following two empirical questions. First, if an NP has only a temporally dependent reading, must this NP necessarily be understood de dicto? The answer is 'no'. Example (18) shows that a bare plural NP (temporally dependent reading) is grammatical with Indicative (de re). Second, if an NP is understood de dicto, must this NP have exclusively a temporally dependent reading? The answer is 'yes'. The indefinite NP with Subjunctive in (19) (de dicto) is necessarily temporally dependent.

(18) En 1990, Juan estaba buscando a profesores que podían hablar 7 idiomas. In 1990 J. was looking-for A professors that could-IND speak 7 lgs 'In 1990, Juan was looking for professors that could-IND speaks 7 lgs.'

(19) En 1990 Juan estaba buscando a un profesor que pudiese hablar 7 idiomas. In $1990 \mathrm{~J}$. was looking-for A a professor that could-SUBJ speak 7 lgs 'In 1990 Juan was looking for a professor that could-SUBJ speak 7 lgs.'

This means that being the dicto entails being temporally dependent, but being temporally dependent does not entail being de dicto. We have seen that $b e_{\text {SPEC }}$ displays a type of temporal dependence with respect to XP1, namely Tense Harmony. The question is, then, whether be $e_{\mathrm{SPC}}$ is also an intensional verb with respect to XP1. If it is, strategy II should be followed, since strategy II will derive temporal dependence and intensionality at the same time. If be SPEC is not an intensional verb with respect to XP1, then we should take strategy I, which will derive temporal dependence without intensionality. 


\section{The Intensionality of Know $+\mathrm{NP}$ and $\mathrm{NP}+B e_{\mathrm{SPEC}}$.}

This section summarizes an argument from Romero (2003). First, in section 3.1, it is shown that certain ambiguity observed in Heim (1979) for (epistemic) know plus a concealed question (CQ) NP must be derived from the fact that, as an intensional verb, know can combine with the NP's extension or with the NP's intension. Section 3.2 then shows that the same ambiguity obtains for the XP1 of $b e_{\mathrm{SPEC}}$ and hence extends the proposed intensional analysis to $b e_{\mathrm{SPEC}}$.

\subsection{Ambiguities for Concealed Question NPs with Know.}

A Karttunen-style semantics for know with an interrogative CP complement is given in (20)-(22). Karttunen's (1977) question meaning in (20) combines with the lexical entry for know in (21) (corresponding to Heim's (1994) strongly exhaustive reading) to yield the truth conditions in (22).

$$
\begin{aligned}
& \llbracket \text { who came } \rrbracket^{\mathrm{g}}=\quad \lambda \mathrm{w} \cdot\{\mathrm{p}: \mathrm{p}(\mathrm{w}) \& \exists \mathrm{x}[\mathrm{p}=\lambda \mathrm{w} \text { ".came }(\mathrm{x}, \mathrm{w} \text { ”) })\} \\
& \llbracket k n o w_{\mathrm{CP}} \rrbracket^{\mathrm{g}}=\lambda \mathrm{q}_{<\mathrm{s},<\mathrm{st}, \mathrm{t}>>} \lambda \mathrm{x}_{\mathrm{e}} \lambda \mathrm{w} . \forall \mathrm{w}^{\prime} \in \operatorname{Dox}_{\mathrm{x}}(\mathrm{w})\left[\mathrm{q}\left(\mathrm{w}^{\prime}\right)=\mathrm{q}(\mathrm{w})\right]
\end{aligned}
$$

$\llbracket$ John knows who came $\rrbracket^{\mathrm{g}}=$

$\lambda \mathrm{w} . \forall \mathrm{w}^{\prime} \in \operatorname{Dox}_{\mathrm{j}}(\mathrm{w})\left[\left\{\mathrm{p}: \mathrm{p}\left(\mathrm{w}^{\prime}\right) \& \exists \mathrm{x}\left[\mathrm{p}=\lambda \mathrm{w}^{\prime \prime} \cdot \operatorname{came}\left(\mathrm{x}, \mathrm{w}^{\prime \prime}\right)\right]\right\}=\right.$ $\{\mathrm{p}: \mathrm{p}(\mathbf{w}) \& \exists \mathrm{x}[\mathrm{p}=\lambda \mathrm{w}, \cdot \operatorname{came}(\mathrm{x}, \mathrm{w} ")]\} \quad]$

A parsimonious extension of this analysis to know plus CQ would hold the following tenets. Take the contribution of the NP the capital of Italy in (23) to be the individual concept spelled out in (24). Know $\mathrm{CQ}$ in (25) is like $k n o w_{\mathrm{CP}}$ in (21) except that the former takes as its argument an individual concept -a function from worlds to (possibly plural) individuals- and the later takes a question meaning -a function from worlds to sets of propositions. The truth conditions for (23) are given in (26). Roughly, taking $\underline{Y}_{<s e>}$ to stand for $\underline{\underline{x}}<s, \mathrm{e}>$ [capital-of-Italy( $\left.\underline{\mathbf{x}}\right)$ ], (26) says that John knows the capital of Italy at w iff John is at w able to identify the value $y(w)$ that $y$ yields when applied to $w$ (see Heim 1979, p. 56).

(23) John knows the capital of Italy.

(24) 【the capital of Italy $\rrbracket^{\mathrm{g}}=\underline{\mathrm{x}} \underline{\mathrm{x}}<\mathrm{s}, \mathrm{e}>$ [capital-of-Italy( $\left.\left.\underline{\mathrm{x}}\right)\right]$

$$
\llbracket k_{n o w} \rrbracket_{\mathrm{CQ}} \rrbracket^{\mathrm{g}}=\lambda \mathrm{y}_{<\mathrm{s}, \mathrm{e}} \lambda \lambda \mathrm{x}_{\mathrm{e}} \lambda \mathrm{w} . \forall \mathrm{w}^{\prime} \in \operatorname{Dox}_{\mathrm{x}}(\mathrm{w})\left[\mathrm{y}\left(\mathrm{w}^{\prime}\right)=\mathrm{y}(\mathrm{w})\right]
$$

(26) 【John knows the capital of Italy $\rrbracket^{\mathrm{g}}=$ $\lambda w . \forall w^{\prime} \in \operatorname{Dox}_{\mathrm{j}}(\mathrm{w})\left[\underline{\mathrm{l}} \underline{\mathrm{x}}<\mathrm{s}, \mathrm{e}>[\operatorname{capital}-\mathrm{of}-\operatorname{Italy}(\underline{\mathrm{x}})]\left(\mathbf{w}^{\prime}\right)=\right.$

$$
\left.\underline{\imath} \underline{x}_{<s, e>}[\text { capital-of-Italy }(\underline{x})](w)\right]
$$


With this background, we turn now to Heim's (1979) ambiguity. Heim notes that example (27) is ambiguous between two readings. Reading A, paraphrasable as "John knows the same price as Fred", is given a scenario in (28). Reading B, paraphrasable as "John knows which price Fred knows", is exemplified in (29).

John knows the price that Fred Knows.

\section{Reading A:}

There are several relevant questions about prices:

"How much is the milk?"

"How much is the oil?"

"How much is the ham?"

Fred knows the answer to one of these questions, e.g., to the first one.

John knows the answer to this question too.

\section{(29) Reading B:}

There are several relevant questions about prices:

"How much is the milk?"

"How much is the oil?"

"How much is the ham?"

Fred knows the answer to one of these questions, e.g., to "How much is the milk?".

Then, there is the "meta-question" asking which of these questions is the one whose answer Fred knows.

John knows the answer to that meta-question. I.e., John knows that the question about prices whose answer Fred knows is "How much is the milk?".

The question then arises, what the source of this ambiguity is. Two attempts will be made at deriving the ambiguity using exclusively the intensional object denoted by the CQ NP, that it, using exclusively the extension of the CQ NP. Figure (30) applies the standard syntax and semantic computation for extensions to the NP the price that Fred knows. Based on (30), the first attempt will try to derive the ambiguity from the binding of the world variable $w$ ' in the predicates price and know in (30). The second attempt will toy with the semantic type of the trace. Note that, whatever type $\sigma$ we decide $t_{l}$ has, it will carry over to the top of the NP tree in (30): $\sigma$ will be the type of the $\lambda$-abstracted $\underline{x}$ in the CP denotation (thus, the CP denotes a set of objects of type $\sigma$ ), and $\sigma$ will also be the type of the unique object $\underline{x}_{\sigma}[\ldots]$ referred to by the NP (that is, $\llbracket$ the $\rrbracket^{\mathrm{g}}$ picks the unique object in $\llbracket C P \rrbracket^{\mathrm{g}} \cap \llbracket$ price $\rrbracket^{\mathrm{g}}$ ). Both attempts will be shown to fail. Once purely extensional analyses have been dismissed, we will turn to the present 
proposal: as an intensional verb, know can combine with the extension or with the intension of its NP complement.

the price that Fred knows

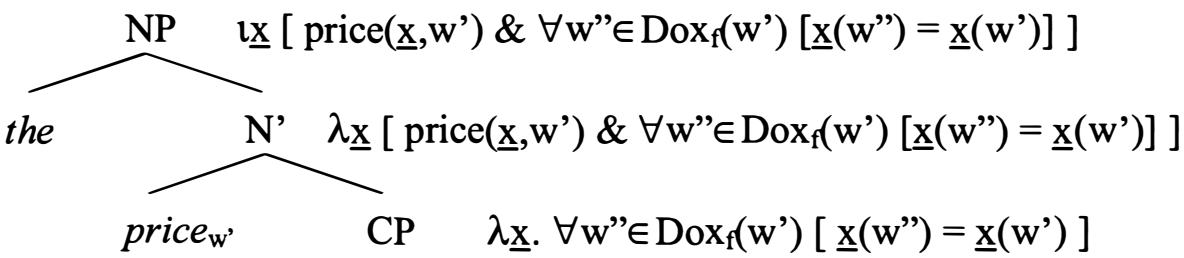

$\lambda \underline{x} \cdot \operatorname{price}\left(\underline{\mathrm{x}}, \mathrm{w}^{\prime}\right)$

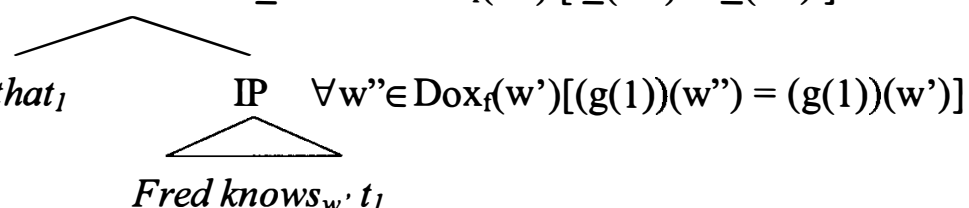

ATTEMPT 1 capitalizes on the world variable of the predicates price and (embedded) know, marked as ?? in (31). The question is: can we derive the two readings from the two possibilities of w-binding in (31), namely binding by the $\lambda$ abstractor $\lambda w$ and binding by the universal quantifier $\forall w$ ' over Fred's doxastic alternatives?

John knows the price that Fred knows.

$\lambda w . \forall w^{\prime} \in \operatorname{Dox}_{\mathrm{j}}(\mathrm{w})$

$\left[\underline{\mathrm{l}}_{<\mathrm{s}, \mathrm{e}>}\left[\mathrm{price}(\underline{\mathrm{x}}, ? ?) \& \forall \mathrm{w}^{\prime \prime} \in \operatorname{Dox}_{\mathrm{f}}(? ?)\left[\underline{\mathrm{x}}\left(\mathrm{w}^{\prime \prime}\right)=\underline{\mathrm{x}}(? ?)\right]\right]\left(\mathrm{w}^{\prime}\right)=\right.$

$\left.\underline{\underline{x}}<s, \mathrm{e}>\left[\operatorname{price}(\underline{\mathrm{x}}, ? ?) \& \forall \mathrm{w}^{\prime \prime} \in \operatorname{Dox}_{\mathrm{f}}(? ?)[\underline{\mathrm{x}}(\mathrm{w} ")=\underline{\mathrm{x}}(? ?)]\right](\mathrm{w})\right]$

Binding by $\lambda w$ produces the truth conditions (32), which correspond to reading A:

Reading A: "John knows the same price that Fred knows."

$\lambda w . \forall w^{\prime} \in \operatorname{Dox}_{j}(w)$

$\left[\underline{\mathrm{l}} \underline{\mathrm{x}}<\mathrm{s}, \mathrm{e}>\left[\operatorname{price}(\underline{\mathrm{x}}, \mathbf{w}) \& \forall \mathrm{w}^{\prime \prime} \in \operatorname{Dox}_{\mathrm{f}}(\mathbf{w})\left[\underline{\mathrm{x}}\left(\mathrm{w}^{\prime \prime}\right)=\underline{\mathrm{x}}(\mathrm{w})\right]\right]\left(\mathrm{w}^{\prime}\right)=\right.$ $\left.\underline{\underline{\mathrm{X}}}<\mathrm{s}, \mathrm{e}>\left[\operatorname{price}(\underline{\mathrm{x}}, \mathbf{w}) \& \forall \mathrm{w}^{\prime \prime} \in \operatorname{Dox}_{\mathrm{f}}(\mathbf{w})[\underline{\mathrm{x}}(\mathrm{w})=,\underline{\mathrm{x}}(\mathrm{w})]\right](\mathrm{w}) \quad\right]$

But the truth conditions resulting from binding by $\forall$ w', spelled out in (33), do not match reading B. To see this, consider the scenario in (34), where John knows what question $\underline{\mathrm{X}}<\mathrm{s}, \mathrm{e}>$ Fred knows the answer to, but John does not know the answer to question $\underline{\mathbf{x}}<s, e>$ itself. Reading B -meaning "John knows what price Fred knows"- is compatible with this scenario. But the truth conditions in (33) yield FALSE in this scenario. (33) yields FALSE because the equality $\underline{\underline{x}}<\mathrm{s}, \mathrm{e}>[\ldots]\left(\mathrm{w}^{\prime}\right)=$ $\underline{\underline{\mathrm{x}}}<\mathrm{s}, \mathrm{e}>[\ldots](\mathrm{w})$ requires that the actual value $\underline{\mathrm{x}}(\mathrm{w})$ of $\underline{\mathrm{X}}<\mathrm{s,e}, \mathrm{e}-$ where $\underline{\mathrm{X}}<\mathrm{s,e}$ > is the question that John thinks (correctly in our scenario) that Fred knows- be also identifiable by John. 


$$
\begin{aligned}
& \lambda w . \forall w^{\prime} \in \operatorname{Dox}_{j}(w) \\
& {\left[\underline{l}^{\underline{x}}<s, e>\left[\operatorname{price}\left(\underline{\mathrm{x}}, \mathbf{w}^{\prime}\right) \& \forall \mathrm{w}^{\prime \prime} \in \operatorname{Dox}_{\mathrm{f}}\left(\mathbf{w}^{\prime}\right)\left[\underline{\mathrm{x}}\left(\mathrm{w}^{\prime \prime}\right)=\underline{\mathrm{x}}\left(\mathrm{w}^{\prime}\right)\right]\right]\left(\mathrm{w}^{\prime}\right)=\right.} \\
& \left.\underline{\underline{\mathrm{X}}}<\mathrm{s,e>}>\left[\operatorname{price}\left(\underline{\mathrm{x}}, \mathrm{w}^{\prime}\right) \& \forall \mathrm{w}^{\prime \prime} \in \operatorname{Dox}_{\mathrm{f}}\left(\mathrm{w}^{\prime}\right)\left[\underline{\mathrm{x}}\left(\mathrm{w}^{\prime \prime}\right)=\underline{\mathrm{x}}\left(\mathrm{w}^{\prime}\right)\right]\right](\mathrm{w})\right]
\end{aligned}
$$

(34) SCENARIO: John correctly thinks that Fred knows how much the milk costs and that Fred knows no other price. But John himself does not know how much the milk costs.

Since (33) does not correspond to reading B and there is no other possible w-binder in the formula to derive this reading, attempt 1 is dismissed.

ATTEMPT 2 manipulates the type of the trace $t_{1}$ to derive the two readings. The intuition is that, whereas in reading A the matrix subject John knows the answer to a simple price question, in reading $B$ he knows the answer to a price "meta-question". In terms of types, according to reading A John is able to identify the actual value $\underline{\underline{X}}<s, e>(w)$ of a given $\underline{\underline{X}}<s, e>$, whereas according to reading B John is able to identify the actual value $\underline{\mathrm{X}}<\mathrm{s,se}>(\mathrm{w})$ of a given $\underline{\mathrm{X}}<\mathrm{s,se}>$. Since the (extensional) type of the entire NP stems from the type of the trace $t_{l}$, attempt 2 capitalizes on the type of the trace.

Taking the type of the trace to be $<\mathrm{s}$, e $>$, we arrive at the correct truth conditions for reading $\mathrm{A}$ in (35). For that, we use the lexical entry for know that we already had in (25), repeated here as know ${ }_{l}$ in (36b), and a parallel lexical entry for price $_{1}$ in (36a).

Reading A: "John knows the same price that Fred knows."

$\lambda \mathrm{w} . \forall \mathrm{w}^{\prime} \in \operatorname{Dox}_{\mathrm{j}}(\mathrm{w})$

$\left[\underline{l} \underline{\mathrm{x}}<\mathrm{s}, \mathrm{e}>\left[\operatorname{price}(\underline{\mathrm{x}}, \mathrm{w}) \& \forall \mathrm{w}^{\prime \prime} \in \operatorname{Dox}_{\mathrm{f}}(\mathrm{w})\left[\underline{\mathrm{x}}\left(\mathrm{w}^{\prime \prime}\right)=\underline{\mathrm{x}}(\mathrm{w})\right]\right]\left(\mathrm{w}^{\prime}\right)=\right.$ $\left.\underline{\mathrm{l}}<\mathrm{s}, \mathrm{e}>\left[\operatorname{price}(\underline{\mathrm{x}}, \mathrm{w}) \& \forall \mathrm{w}^{\prime \prime} \in \operatorname{Dox}_{\mathrm{f}}(\mathrm{w})[\underline{\mathrm{x}}(\mathrm{w})=,\underline{\mathrm{x}}(\mathrm{w})]\right](\mathrm{w})\right]$
a. $\llbracket$ price $_{1} \rrbracket^{\mathrm{g}}(\underline{\mathrm{x}}<\mathrm{s}, \mathrm{e}>)(\mathrm{w})=1$ iff $\operatorname{price}(\underline{\mathrm{x}}, \mathrm{w})$
b. $\llbracket k n o w_{l} \rrbracket^{\mathrm{g}}(\underline{\mathrm{x}}<\mathrm{s}, \mathrm{e}>)(\mathrm{z})(\mathrm{w})=1$ iff $\forall \mathrm{w}^{\prime} \in \operatorname{Dox}_{\mathrm{z}}(\mathrm{w})\left[\underline{\mathrm{x}}\left(\mathrm{w}^{\prime}\right)=\underline{\mathrm{x}}(\mathrm{w})\right]$

If the type of the trace is $\langle\mathrm{s},<\mathrm{s}, \mathrm{e}>>$ instead, we derive the truth conditions in (37). (37) corresponds (roughly) to reading B. ${ }^{2}$ Note, though, that in order to generate these truth conditions, we need not only the lexical entries price $_{2}$ and know $_{2}$ in (38) -crosscategorial variants for those in (36)- but also the entry know 3 in (38c). $\llbracket k n o w_{3} \rrbracket^{\mathrm{g}}$ is needed as the meaning of embedded know, so that the embedded subject Fred is said to be able to identity the actual value $[\underline{\mathrm{x}}<\mathrm{s,se}>$

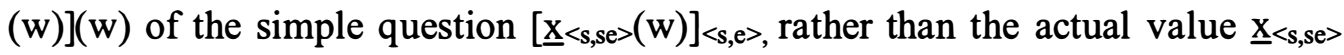
(w) of the meta-question $\underline{\underline{x}}<$ s,se> .

(37) Reading B: "John knows what price Fred knows." $\lambda w . \forall w^{\prime} \in \operatorname{Dox}_{j}(w)$ 
$\left[\underline{\mathrm{l}} \underline{\mathrm{x}}_{\mathrm{s},<\mathrm{se}>>}\left[\operatorname{price}(\underline{\mathrm{x}}(\mathrm{w}), \mathrm{w}) \& \forall \mathrm{w}^{\prime \prime} \in \operatorname{Dox}_{\mathrm{f}}(\mathrm{w})[\underline{\mathrm{x}}(\mathrm{w})(\mathrm{w})=,\underline{\mathrm{x}}(\mathrm{w})(\mathrm{w})]\right]\left(\mathrm{w}^{\prime}\right)=\right.$ $\left.\underline{\underline{\mathrm{X}}}<\mathrm{s},<\operatorname{se}>>\left[\operatorname{price}(\underline{\mathrm{x}}(\mathrm{w}), \mathrm{w}) \& \forall \mathrm{w} " \in \operatorname{Dox}_{\mathrm{f}}(\mathrm{w})[\underline{\mathrm{x}}(\mathrm{w})(\mathrm{w})=\underline{\mathrm{x}}(\mathrm{w})(\mathrm{w})]\right](\mathrm{w}) \quad\right]$
a. $\llbracket$ price $_{2} \rrbracket^{\mathrm{g}}(\underline{\mathrm{x}}<\mathrm{s}, \mathrm{se}>)(\mathrm{w})=1$ iff $\operatorname{price}(\underline{\mathrm{x}}(\mathrm{w}), \mathrm{w})$
b. $\llbracket k n o w_{2} \rrbracket^{\mathrm{g}}(\underline{\mathrm{x}}<\mathrm{s}, \mathrm{se}>)(\mathrm{z})(\mathrm{w})=1$ iff $\forall \mathrm{w}^{\prime} \in \operatorname{Dox}_{\mathrm{z}}(\mathrm{w})\left[\underline{\mathrm{x}}\left(\mathrm{w}^{\prime}\right)=\underline{\mathrm{x}}(\mathrm{w})\right]$
c. $\llbracket k n o w_{3} \rrbracket^{\mathrm{g}}(\underline{\mathrm{x}}<\mathrm{s}, \mathrm{se}>)(\mathrm{z})(\mathrm{w})=1$ iff $\forall \mathrm{w}^{\prime} \in \operatorname{Dox}_{\mathrm{z}}(\mathrm{w})\left[\underline{\mathrm{x}}(\mathrm{w})\left(\mathrm{w}^{\prime}\right)=\underline{\mathrm{x}}(\mathrm{w})(\mathrm{w})\right]$

The problem with attempt 2 is the following. Let us concede that we have all the lexical entries listed above. We can combine these lexical entries in several ways. Two possibilities are these:

i. John and Fred know the same exact question, i.e., we plug in the same number of $w$ variables for John's $\underline{x}[\ldots]$ and for Fred's $\underline{x}$, using only knowl.

\section{Reading A}

ii. John knows a higher meta-question than Fred, i.e., we plug in fewer w variables for John's $\underline{\underline{x}}[\ldots]$ than for Fred's $\underline{x}$, using know 2 for John and know $_{3}$ for Fred.

\section{Reading B}

Interestingly, possibility (iii) is missing:

iii. Fred knows a higher meta-question than John, i.e., we plug in more w variables for John's $\underline{\underline{x}}[\ldots]$ than for Fred's $\underline{x}$, using know ${ }_{3}$ for John and know $_{2}$ for Fred.

\section{Reading B'}

We know that possibility (iii) is missing because, if available, (39) would also have the inverse of reading B, namely the reading B' spelled out in (40). Using scenario (41) for illustration, (40) roughly says that the meta-question $\underline{\mathrm{X}}<\mathrm{s},<\mathrm{se}>>$ whose answer is known to Fred (where $\underline{\underline{X}}<\mathrm{s},<\mathrm{se}>>$ is "What price does John know? in our scenario) is such that its actual answer $\underline{\underline{x}}<<,<\operatorname{se}>[\ldots](\mathrm{w})$ (where $\underline{\underline{l}} \underline{x}_{<,<s e>>}[\ldots](\mathrm{w})$ is "How much does the milk cost?") is a question whose answer is known to John. Thus, if sentence (39) had this reading B', sentence (39) would be true in scenario (41). But sentence (39) is judged false in scenario (41).

(39) John knows the price that Fred knows.

(40) Reading B':

$\lambda \mathrm{w} . \forall \mathrm{w}^{\prime} \in \operatorname{Dox}_{\mathrm{j}}(\mathrm{w})$

$\left[\underline{\mathrm{x}}<\mathrm{s},<\mathrm{se}>>\left[\operatorname{price}(\underline{\mathrm{x}}(\mathrm{w}), \mathrm{w}) \& \forall \mathrm{w}^{\prime \prime} \in \operatorname{Dox}_{\mathrm{f}}(\mathrm{w})[\underline{\mathrm{x}}(\mathrm{w})=,\underline{\mathrm{x}}(\mathrm{w})]\right](\mathrm{w})(\mathrm{w})=\right.$ $\left.\underline{\mathrm{t}}<\mathrm{s},<\operatorname{se}>>\left[\operatorname{price}(\underline{\mathrm{x}}(\mathrm{w}), \mathrm{w}) \& \forall \mathrm{w}^{\prime \prime} \in \operatorname{Dox}_{\mathrm{f}}(\mathrm{w})[\underline{\mathrm{x}}(\mathrm{w} ")=\underline{\mathrm{x}}(\mathrm{w})]\right](\mathrm{w})(\mathrm{w}) \quad\right]$

(41) SCENARIO: John knows that the milk costs $\$ 1.97$, and he does not know the answer to any other price question. Fred knows what price John knows -namely, the price of milk-, but Fred does not know how much the milk costs, nor does Fred know any other price (meta)-question. 
Given the lexical entries that we need to generate readings $\mathrm{A}$ and $\mathrm{B}$-in particular, given that we need $k n o w_{3}$ in addition to the more standard know 1 and know $_{2}$, there is no way to rule out compositionally the unavailable reading B'.

Once purely extensional analyses of the NP have been ruled out, ATTEMPT 3 presents my proposal: both the extension and the intension of the NP can provide the semantic argument of know.

An intensional verb like look for takes an intensional object as its argument (Zimmermann 1992, Moltmann 1997, among many others). This intensional object is often provided directly by the intension of its complement $\mathrm{NP}$, as in (42). But this intensional object can also arise from the extension of a higher type NP. This second possibility is illustrated in (43), which has a de dicto reading on the extension of the NP that makes it true in scenario (44):

(42) John is looking for the unicorn with the longest horn.

a. 'In all of John's bouletic alternatives $w$ ' in $w$ : John finds in $w$ ' the $x_{e}$ that is the unicorn with the longest horn in w' (whichever that may be).'

(43) John is looking for the unicorn Fred is looking for (: the one with the longest horn.)

a. 'Each $\mathrm{x}$ out of John and Fred is such that, in all of $\mathrm{x}$ 's bouletic alternatives $w^{\prime}$ in $w$ : $x$ finds in $w$ ' the individual $x_{e}$ that is the unicorn with the longest horn in w' (whichever that may be).'

(44) SCENARIO: John does not have any beliefs as to which unicorn has the longest horn. He wants to catch the unicorn with the longest horn, whichever that may be. Exactly the same holds for Fred.

I propose that the choice between the NP's extension and intension is the source of the ambiguity between reading $\mathrm{A}$ and reading $\mathrm{B}$. More concretely, reading A obtains when the NP's extension is used, whereas reading B follows when know combines with the NP's intension. This is sketched in (45):

(45) John knows the price that Fred knows.

a. Reading A: $\llbracket k n o w \rrbracket^{\mathrm{g}}+$ EXTENSION of [NP the price that Fred knows].

b. Reading B: $\llbracket k n o w \rrbracket^{\mathrm{g}}+$ INTENSION of [NP the price that Fred knows].

The proposed analysis is spelled out in (46) through (49). Only the lexical entries in (46) are needed (which crucially exclude know $_{3}$ ). The intension of the NP the price that Fred knows is computed in (47). To obtain reading A, we take the intension built in (47) and we apply it to the actual world $w_{0}$ to generate the NP's extension. This extension - which is itself an intensional object of type $<\mathrm{s}, \mathrm{e}>-$ is then used as the argument of the matrix verb $\left(\right.$ know $\left._{1}\right)$. The result is (48), 
which truth-conditionally corresponds to reading $\mathrm{A}$. To derive reading $\mathrm{B}$, we take the intension built in (47) and combine it directly with the matrix verb (know 2$)$. We obtain the truth conditions in (49), which match reading B.
a. $\llbracket$ price $_{1} \rrbracket^{\mathrm{g}}(\underline{\mathrm{x}}<\mathrm{s}, \mathrm{e}>)(\mathrm{w})=1 \quad$ iff $\quad \operatorname{price}(\underline{\mathrm{x}}, \mathrm{w})$
b. $\llbracket k n o w_{l} \rrbracket^{\mathrm{g}}(\underline{\mathrm{x}}<\mathrm{s}, \mathrm{e}>)(\mathrm{z})(\mathrm{w})=1 \quad$ iff $\quad \forall \mathrm{w}^{\prime} \in \operatorname{Dox}_{\mathrm{z}}(\mathrm{w})\left[\underline{\mathrm{x}}\left(\mathrm{w}^{\prime}\right)=\underline{\mathrm{x}}(\mathrm{w})\right]$
c. $\llbracket k n o w_{2} \rrbracket^{\mathrm{g}}(\underline{\mathrm{x}}<\mathrm{s}, \mathrm{se}>)(\mathrm{z})(\mathrm{w})=1 \quad$ iff $\quad \forall \mathrm{w}^{\prime} \in \operatorname{Dox}_{\mathrm{z}}(\mathrm{w})\left[\underline{\mathrm{x}}\left(\mathrm{w} \mathrm{w}^{\prime}\right)=\underline{\mathrm{x}}(\mathrm{w})\right]$

(47) the price that Fred knows

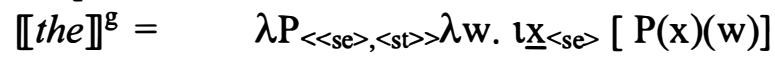

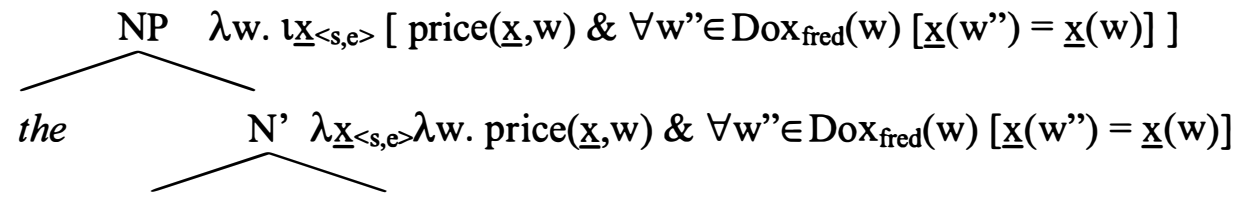

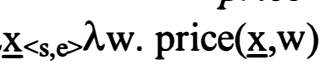
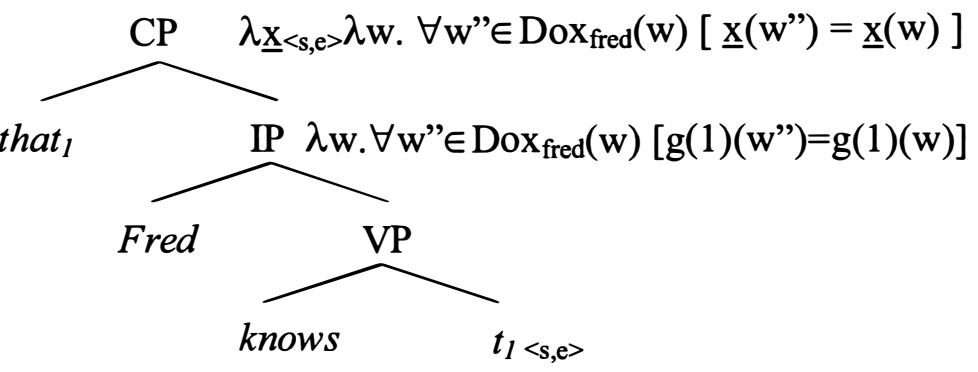

$\lambda \underline{\mathrm{x}}<\mathrm{s}, \mathrm{e}>\lambda \mathrm{z}_{\mathrm{e}} \lambda \mathrm{w} . \forall \mathrm{w} " \in \operatorname{Dox}_{\mathrm{z}}(\mathrm{w})[\underline{\mathrm{x}}(\mathrm{w} ")=\underline{\mathrm{x}}(\mathrm{w})] \quad \mathrm{g}(1)$

(48) Reading A: "John knows the same price as Fred knows."

$\lambda \mathrm{w}_{0} . \forall \mathrm{w}^{\prime} \in \operatorname{Dox}_{\text {john }}\left(\mathrm{w}_{0}\right)$

$\left[\quad \underline{\mathrm{x}}_{<\mathrm{se}}>\left[\operatorname{price}\left(\underline{\mathrm{x}}, \mathrm{w}_{0}\right) \& \forall \mathrm{w}^{\prime \prime} \in \operatorname{Dox}_{\mathrm{fred}}\left(\mathrm{w}_{0}\right)\left[\underline{\mathrm{x}}\left(\mathrm{w}^{\prime \prime}\right)=\underline{\mathrm{x}}\left(\mathrm{w}_{0}\right)\right]\right] \quad\left(\mathrm{w}^{\prime}\right)=\right.$

$\left.\underline{\underline{\mathrm{X}}}<\operatorname{se}>\left[\operatorname{price}\left(\underline{\mathrm{x}}, \mathrm{w}_{0}\right) \& \forall \mathrm{w}^{\prime \prime} \in \operatorname{Dox}_{\mathrm{fred}}\left(\mathrm{w}_{0}\right)\left[\underline{\mathrm{x}}\left(\mathrm{w}^{\prime \prime}\right)=\underline{\mathrm{x}}\left(\mathrm{w}_{0}\right)\right]\right] \quad\left(\mathrm{w}_{0}\right)\right]$

(49) Reading B: "John knows what price Fred knows."

$\lambda \mathrm{w}_{0} . \forall \mathrm{w}^{\prime} \in \operatorname{Dox}_{\mathrm{john}}\left(\mathrm{w}_{0}\right)$

$\left[\lambda w . \underline{\mathrm{x}}<\mathrm{se}>\left[\operatorname{price}(\underline{\mathrm{x}}, \mathrm{w}) \& \forall \mathrm{w}^{\prime \prime} \in \operatorname{Dox}\right.\right.$ fred $\left.(\mathrm{w})\left[\underline{\mathrm{x}}\left(\mathrm{w}^{\prime \prime}\right)=\underline{\mathrm{x}}(\mathrm{w})\right]\right] \quad\left(\mathrm{w}^{\prime}\right)=$

$\lambda$ w. $\underline{\underline{x}}<$ se> $\left.\left[\operatorname{price}(\underline{\mathrm{x}}, \mathrm{w}) \& \forall \mathrm{w}^{\prime \prime} \in \operatorname{Dox}_{\mathrm{fred}}(\mathrm{w})[\underline{\mathrm{x}}(\mathrm{w} ")=\underline{\mathrm{x}}(\mathrm{w})]\right] \quad\left(\mathrm{w}_{0}\right) \quad\right]$

In sum, the ambiguity between reading A and B with know derives from the fact that know can take as its semantic argument the extension or the intension of its complement NP, as other intensional verbs can.

\subsection{Ambiguities for NP Subjects of Specificational Be.}

Interestingly, note that the same ambiguity found with CQ NPs with know is found in the XP1 subject of be SPEC. For example, the NP the price that Fred 
thought was $\$ 1.29$ yields reading A in example (50), exemplified in (51), and it yields reading B in (52), exemplified in (53).

(50) The price that Fred thought was $\$ 1.29$ was (actually) $\$ 1.79$.

(51) Reading A: "The question whose answer Fred thought was ' $\$ 1.29$ ' has as its real answer ' $\$ 1.79$ '."

There are several relevant questions about prices:

"How much is the milk?"

"How much is the oil?"

"How much is the ham?"

For one of these questions, Fred thought the answer was ' $\$ 1.29$ '.

But the actual answer to that question is ' $\$ 1.79$ '.

(52) The price that Fred thought was $\$ 1.29$ was the price of milk.

(53) Reading B: "The question whose answer Fred thought was ' $\$ 1.29$ ' is

'How much is the milk?'.'

There are several relevant questions about prices:

"How much is the milk?"

"How much is the oil?"

"How much is the ham?"

For one of these questions, Fred thought the answer was ' $\$ 1.29$ '.

Then, there is the "meta-question" asking which of these questions is the one whose answer Fred thought was $\$ 1.29$.

The answer to the meta-question is "How much is the milk?".

That is, Fred thought that the price of milk is $\$ 1.29$.

Are the sentences (51) and (52) specificational as opposed to predicational? That (51) is a specificational sentence is hardly arguable: it is like the sentence The price of milk is $\$ 1.79$ except for the choice of definite description. As for (52), the intended meaning involves a de dicto reading of the post-copular phrase the price of milk under thought. This is an instance of Opacity Connectivity, a trait of specificational but not of predicational sentences, as we saw in section 1. As a further test, take scenario (54) and the sentences (55)-(56), which display Variable Binding Connectivity. (55) illustrates reading A and (56) exemplifies reading $\mathrm{B}$.

(54) SCENARIO for (55)-(56): A group of 2-year old girls from the Ukraine was given in adoption to several families in Barcelona. The director of the adoption program encouraged the biological relatives of each girl to keep in touch with her by writing letters, telling them though that they should not identify themselves using their name or family relationship. After a couple of years, the girls have developed some hypotheses on who every 
secret writer may or may not be. For example, no girl thinks that the one who writes to her the least can possibly be her mother. In fact, they are all right, since, for every girl, the one who writes to her the least is her uncle.

\section{Reading A:}

The anonymous writer that no girl $l_{1}$ thinks can possibly be her ${ }_{1}$ mother is (in fact) her 1 uncle.

\section{Reading B:}

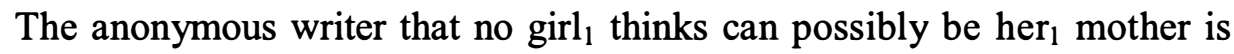
the one who writes to her 1 the least.

I propose to analyze the ambiguity arising for NP subjects of be $e_{\text {SPEC }}$ in a way parallel to the ambiguity with NP objects of know. Be $e_{\mathrm{SPEC}}$ is an intensional verb needing an intensional object as its semantic argument. This intensional object can be drawn from the extension of its NP subject (reading A) or from the NP's intension (reading B), as summarized in (57). The (crosscategorial) lexical entries for be $e_{S P C C}$ are given in (58). From (57)-(58) the truth conditions in (59) and (60) are derived, which correspond to reading A and reading B respectively.

(57) The price that Fred thought was $\$ 1.29$ was ...

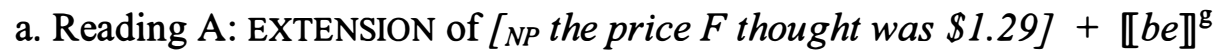

b. Reading B: INTENSION of [NP the price $F$ thought was $\$ 1.29]+\llbracket b e \rrbracket^{\mathrm{g}}$
a. $\llbracket b e_{1} \rrbracket^{\mathrm{g}}\left(\mathrm{y}_{\mathrm{e}}\right)(\underline{\mathrm{x}}<\mathrm{s}, \mathrm{e}>)(\mathrm{w})=1$
iff $\quad \underline{x}(w)=y$

b. $\llbracket b e_{2} \rrbracket^{\mathrm{g}}\left(\mathrm{y}_{<\mathrm{s}, \mathrm{e}>}\right)(\underline{\mathrm{x}}<\mathrm{s}, \mathrm{se}>)(\mathrm{w})=1 \quad$ iff $\quad \underline{\mathrm{x}}(\mathrm{w})=\mathrm{y}$

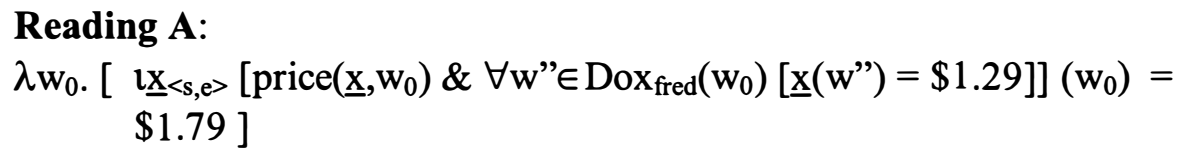

\section{(60) Reading B:}

$\lambda w_{0}$. [ $\lambda w . \underline{w}_{<\mathrm{x}, e>}\left[\operatorname{price}(\underline{\mathrm{x}}, \mathrm{w}) \& \forall \mathrm{w}^{\prime \prime} \in \operatorname{Dox}_{\mathrm{fred}}(\mathrm{w})[\underline{\mathrm{x}}(\mathrm{w} ")=\$ 1.29]\right]\left(\mathrm{w}_{0}\right)=$ $\underline{\underline{x}}<s, e>\left[\right.$ price-of-milk $\left.\left(\underline{\mathbf{x}}, \mathrm{w}_{0}\right)\right]$ ]

To sum up section 3, we have seen that the ambiguity between reading A and B with know + NP cannot be derived using exclusively the extension of the NP. The ambiguity follows if, like other intensional verbs, know can draw the intensional object needed as its semantic argument either from the extension (reading A) or from the intension (reading B) of the NP. The same reading A / reading $\mathrm{B}$ ambiguity arises for $\mathrm{NP} 1+b e_{\mathrm{SPEC}}$. I have proposed an analysis parallel to the one for know: be $e_{\mathrm{SPEC}}$ is an intensional verb and can draw the required intensional object from the extension or from the intension of the NP. 


\section{Tense Harmony with Strategy II}

Let us now go back to the Tense Harmony pattern, repeated in (61):
a. [XP1 ...PAST...] PAST
b. [XP1 ...PRES...] PRES
c. $[\mathrm{XP1}$...PAST...] PRES
d. $*[\mathrm{XP1} 1 . . \mathrm{PRES} \ldots]$ PAST

Sharvit's (2003) makes the following assumptions about tense operators (see also Ogihara 1996, Kusumoto 1999). First, she assumes relative semantics for the past tense operator PAST and absolute semantics for the (English) present tense operator PRES. This means that PAST introduces a time t' (type i) preceding the relative evaluation time $\mathrm{t}_{0}$ (which defaults to the speech time if unbound), whereas PRES introduces a time t' that overlaps with the absolute speech time, denoted by now, as sketched in (62)-(63).

$$
\begin{aligned}
& \llbracket P A S T-t_{0} \rrbracket^{\mathrm{g}}=\ldots \text { there is a } \mathrm{t}^{\prime} \text { in } \mathrm{D}_{\mathrm{i}} \text { that precedes } \llbracket t_{0} \rrbracket^{\mathrm{g}} \ldots \\
& \llbracket P R E S-(\text { now }) \rrbracket^{\mathrm{g}}=\quad \ldots \text { there is a } \mathrm{t}^{\prime} \text { in } \mathrm{D}_{\mathrm{i}} \text { that overlaps } \llbracket \text { now } \rrbracket^{\mathrm{g}} \ldots
\end{aligned}
$$

Second, the clusters $P A S T$ - $t_{0}$ and PRES-(now) have an argument slot $\lambda \mathrm{t}$ for a pronominal restrictor, whose function is to delimit the possible range of times t' to a given temporal interval t. The resulting lexical entries are as follows: ${ }^{3}$

$$
\begin{array}{cc}
\llbracket P A S T-\mathrm{t}_{0} \rrbracket^{\mathrm{g}}= & \lambda \mathrm{P}_{<\mathrm{i}, \mathrm{st}} \lambda \lambda \mathrm{t}_{\mathrm{i}} \lambda \mathrm{w}_{\mathrm{s}}, \exists \mathrm{t}^{\prime}\left[\mathrm{t}^{\prime}<\llbracket t_{0} \rrbracket^{\mathrm{g}} \wedge \mathrm{t}^{\prime} \subseteq \mathrm{t} \wedge \mathrm{P}\left(\mathrm{t}^{\prime}\right)(\mathrm{w})=1\right] \\
\llbracket P R E S-(\text { now }) \rrbracket^{\mathrm{g}=} & \lambda \mathrm{P}_{<\mathrm{i}, \mathrm{st}>} \lambda \mathrm{t}_{\mathrm{i}} \lambda \mathrm{w}_{\mathrm{s}} . \exists \mathrm{t}^{\prime}\left[\mathrm{t}^{\prime} \text { overlaps } \llbracket \text { now } \rrbracket^{\mathrm{g}} \wedge \mathrm{t}^{\prime} \subseteq \mathrm{t} \wedge\right. \\
\left.\mathrm{P}\left(\mathrm{t}^{\prime}\right)(\mathrm{w})=1\right]
\end{array}
$$

Sharvit's (2003) proposes that Tense Harmony arises because the tense operator of the matrix clause binds directly (in strategy I) or indirectly (in strategy II) the pronominal restrictor of the embedded tense operator. Direct binding in strategy I produces the LF of sentence (66) in (67a), where the pronominal restrictor $t_{l}$ remains unbound within the NP and is later bound at the matrix level by the index 1 under PAST, hence yielding "direct" binding by PAST. The semantic contribution of the NP is thus (67b). Note that, according to this LF, be $e_{\mathrm{SPC}}$ is atemporal (i.e. it has no temporal argument) and it takes two arguments of the same type $\sigma$. This is captured in the lexical entry (67c).

What John liked was War and Peace. 


\author{
Strategy I: \\ a. PAST- $t_{0}-t_{6} 1$ [ [what PAST- $t_{0}-t_{1} 3$ John liked- $t_{3}$ ] be WP ] \\ b. $\quad \mathrm{Ix}_{\mathrm{e}}\left[\exists \mathrm{t}^{\prime}\left[\mathrm{t}^{\prime}<\llbracket t_{0} \rrbracket^{\mathrm{g}} \wedge \mathrm{t}^{\prime} \subseteq \mathrm{t}_{1} \wedge\right.\right.$ like $\left.\left.\left(\mathrm{j}, \mathrm{x}, \mathrm{t}^{\prime}, \mathrm{w}\right)\right]\right]$ \\ c. $\llbracket b e \rrbracket^{\mathrm{g}}=\lambda \mathrm{X}_{\sigma} \lambda \mathrm{Y}_{\sigma} \cdot \mathrm{Y}=\mathrm{X}$
}

In contrast, strategy II has the pronominal restrictor $t_{2} \lambda$-bound within the NP, as in (68a). The semantic contribution of the NP is thus (68b). Note that this time $b e_{\text {SPEC }}$ combines with a post-copular argument of type $\sigma$ and with a pre-copular argument of type $\left\langle i,\left\langle\mathrm{~s}, \sigma>>\right.\right.$. That is, under strategy II, be $e_{\mathrm{SPEC}}$ is a (temporally) intensional verb with respect to its subject position, as defined in (68c). Be $\mathrm{SPEC}$ has, furthermore, its own temporal argument $t$ in (68c). This variable $t$ will be $\lambda$ converted into the $\lambda \mathrm{t}_{2}$ slot of the NP1 function, and it will be bound at the matrix level under PAST, yielding the effect of "indirect" binding of $t_{2}$ by PAST.

$$
\begin{aligned}
& \text { Strategy II: } \\
& \text { a. PAST- } \left.t_{0}-t_{6}(1)\left[\left[(2) \text { what PAST- } t_{0}\left(-t_{2}\right)(3) \text { John liked(- } t_{3}\right)\right] \text { be(- } t_{1}\right) \text { WP] } \\
& \text { b. } \lambda \mathrm{t}_{2} \lambda \mathrm{w} \cdot \mathrm{lx}_{\mathrm{e}}\left[\exists \mathrm{t}^{\prime}\left[\mathrm{t}^{\prime}<\llbracket t_{0} \rrbracket^{\mathrm{g}} \wedge \mathrm{t}^{\prime} \subseteq \mathrm{t}_{2} \wedge \text { like }\left(\mathrm{j}, \mathrm{x}, \mathrm{t}^{\prime}, \mathrm{w}\right)\right]\right] \\
& \text { c. } \left.\llbracket b e \rrbracket^{\mathrm{g}}=\lambda \mathrm{X}_{\sigma} \lambda \mathrm{Y}_{<\mathrm{i}, \mathrm{s} \sigma}\right\rangle \lambda \mathrm{t}_{\mathrm{i}} \lambda \mathrm{w}_{\mathrm{s}} . \mathrm{Y}(\mathrm{t})(\mathrm{w})=\mathrm{X}
\end{aligned}
$$

We saw in section 2 that there are temporal dependence phenomena which are not related to de dicto readings and which could thus be analyzed in the spirit of strategy I (e.g. bare plural NPs in Spanish). We also saw that de dicto readings enforce temporal dependence. This means that there is no strategy I' -the counterpart of strategy I operating on worlds- deriving world dependence (de dicto readings) and leaving time as possibly independent. Hence, constructions with temporally dependent de dicto readings (e.g. Subjunctive marking in Spanish RCs) must be analyzed as having one and the same source for both effects (temporal/world intensionality in strategy II) and not two different sources (strategy I for times and the non-attested strategy I' for worlds). Given the proposal in section 3 that $b e_{\mathrm{SPEC}}$ is a (world-)intensional verb, I propose that its temporal dependence -Tense Harmony- be derived using strategy II.

Adopting strategy II, let us illustrate Sharvit's idea for the four cases in (61). The full semantic computation for case one, with configuration [IP [XP1...PAST...] PAST ], is spelled out in (69). The final truth conditions at the top of the computation require (among other things) that there be a time interval $t$ " prior to now that embeds a time interval $t$ ' also prior to now. (The relevant parts of the formula are underlined.) These requirements are consistent and hence the configuration [IP [XP1...PAST...] PAST ] is grammatical. Temporal requirements are also consistent for case two in (70), with structure [IP [XP1...PRES...] PRES ], and for case three in (71), with structure [IP [XP1...PAST...] PRES ], making both configurations grammatical as well. In contrast, case four in (72) leads to inconsistency: it requires for there to be a time interval t" (completely) prior to $t_{0}$ 
(=now) that embeds a time interval $t$ ' overlapping with now. As this is impossible, the configuration [IP $[\mathrm{XP1} \ldots$ PRES...] PAST ] is ungrammatical.

Case one: [IP [XP1 ...PAST...] PAST ]

What John liked was War and Peace.

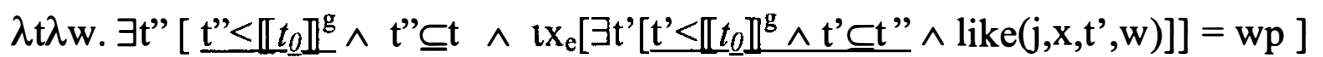

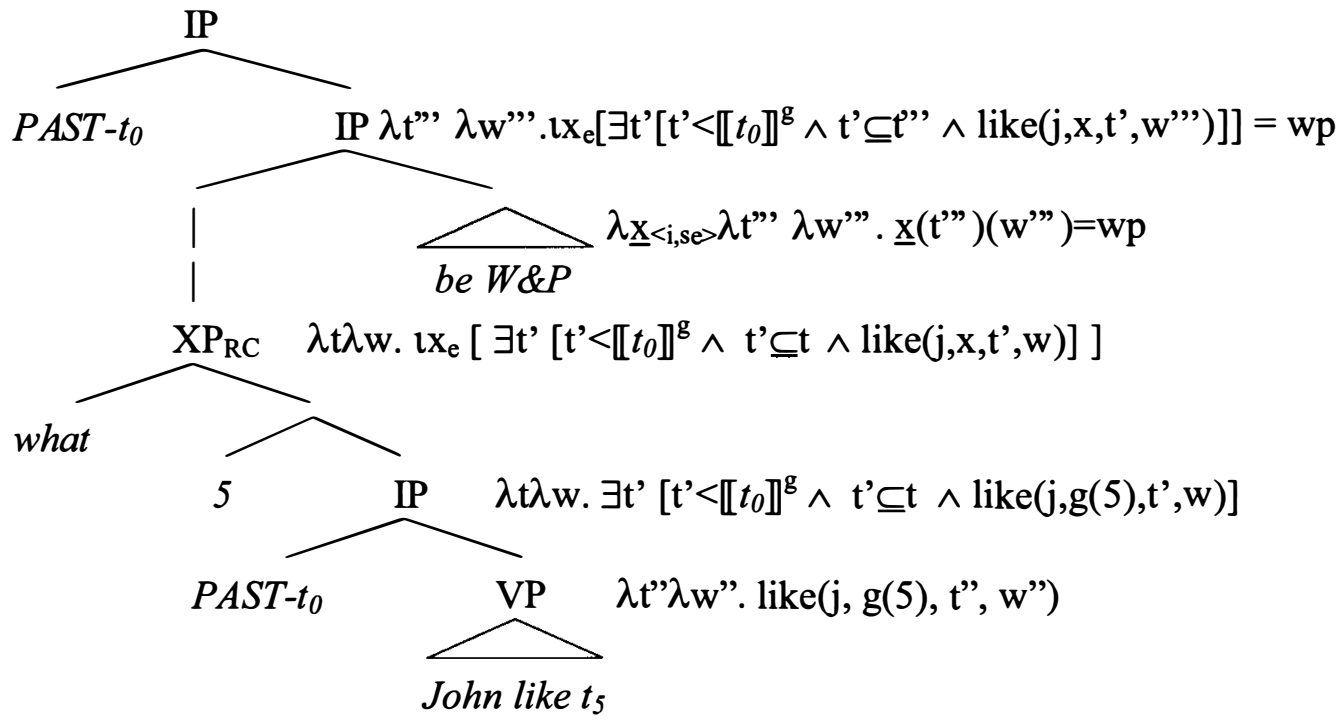

(70) Case two: [IP [XP1 ...PRES...] PRES ]

What John likes is War and Peace.

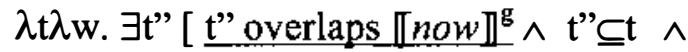
$\mathbf{t x}_{\mathrm{e}}\left[\exists \mathrm{t}^{\prime}\left[\mathrm{t}^{\prime}\right.\right.$ overlaps 【now $\left.\left.\left.\rrbracket^{\mathrm{g}} \wedge \mathrm{t}^{\mathrm{\prime}} \subset \mathrm{t}^{\prime \prime} \wedge \operatorname{like}\left(\mathrm{j}, \mathrm{x}, \mathrm{t}^{\prime}, \mathrm{w}\right)\right]\right]=\mathrm{wp}\right]$

(71) Case three: [IP [XP1 ...PAST...] PRES ]

What John liked is War and Peace.

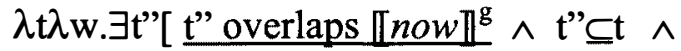

$$
\left.\mathrm{tx}_{\mathrm{e}}\left[\exists \mathrm{t}^{\prime}\left[\mathrm{t}^{\prime}<\llbracket \underline{t}_{0} \mathbb{\Perp}^{\mathrm{g}} \wedge \mathrm{t}^{\prime} \subset \mathrm{t}^{\prime \prime} \wedge \operatorname{like}\left(\mathrm{j}, \mathrm{x}, \mathrm{t}^{\prime}, \mathrm{w}\right)\right]\right]=\mathrm{wp}\right]
$$

(72) Case four: * [IP [XP1 ...PRES...] PAST ]

What John likes was War and Peace.

$\lambda \mathrm{t} \lambda \mathrm{w} . \exists \mathrm{t} "\left[\underline{\mathrm{t} "} \leq \mathbb{L} t_{0} \mathbb{1}^{\mathrm{g}} \wedge \mathrm{t} " \subseteq \mathrm{t} \wedge\right.$

$$
\left.\mathrm{ix}_{\mathrm{e}}\left[\exists \mathrm{t}^{\prime}\left[\mathrm{t}^{\prime} \text { 'overlaps } \llbracket \text { now } \|^{\mathrm{g}} \wedge \mathrm{t}^{\prime} \subset \mathrm{t}^{\prime \prime} \wedge \operatorname{like}\left(\mathrm{j}, \mathrm{x}, \mathrm{t}^{\prime}, \mathrm{w}\right)\right]\right]=\mathrm{wp}\right]
$$

The use of strategy II instead of strategy I makes a further prediction. In the cases examined, the subject NP is temporally dependent on the matrix tense because $b e$ combines with the NP's intension $\lambda t \lambda w . \mathrm{x}_{\mathrm{e}}[\ldots]$. The prediction is that, when be combines with the NP's extension $\mathrm{rx}_{\mathrm{e}}[\ldots]$ in reading $\mathrm{A}$ examples, the requirement of Tense Harmony should disappear. This prediction is borne out, witness the contrast between reading $B$ in (73) and reading $A$ in (74). 
* The price that Fred thinks is $\$ 1.29$ today was the price of milk. Reading B: NP's intension, Tense Harmony required.

(74) The price that Fred thinks is $\$ 1.29$ today was $\$ 1.79$ yesterday. Reading A: NP's extension, no Tense Harmony.

Strategy I does not link Tense Harmony to intensionality. Regardless of whether $b e_{\text {SPEC }}$ semantically combines with the NP's intension or with its extension, the matrix tense operator is expected to bind the embedded pronominal temporal restrictor $\left(t_{l}\right.$ in (67a)). Hence, Tense Harmony is expected to obtain regardless of whether we have reading $\mathrm{A}$ or reading $\mathrm{B}$. This expectation is not borne out.

\section{Conclusions and further issues}

The main points of this paper are the following. First, temporal dependence and (world and temporal) intensionality are different phenomena, connected by an entailment relation: a de dicto NP is necessarily temporally dependent, though a temporally dependent NP can be understood de dicto or de re. Second, as noted in the literature, specificational copular sentences obey Tense Harmony, which can be viewed as a type of temporal dependence. Third, specificational copular sentences involve intensionality. In the same way that know can draw its semantic argument from the intension or from the extension of its object NP to yield the reading $\mathrm{A} /$ reading $\mathrm{B}$ ambiguity, so can specificational be draw its semantic argument from the intension or from the extension of its subject NP. Fourth and finally, strategy II, according to which $b e_{\mathrm{SPEC}}$ is intensional with respect to its subject NP1, gives a unified account of Tense Harmony and the observed intensionality: when $b e_{\mathrm{SPEC}}$ combines with the NP's intension in reading $\mathrm{B}$, Tense Harmony must be obeyed; when $b e_{\mathrm{SPEC}}$ combines with the NP's extension in reading A, no Tense Harmony is required.

A further question is how temporal dependence applies to CQ NPs with know, tell, guess, etc. As with the complement clause in (75), the configuration [PAST [Do...PRES...]] in (76) is deviant except for double-access readings (where the embedded proposition must hold both at speech time and at the time of matrix verb). We would need an analysis of double-access readings that saves the configuration [PAST know [ PRES V] ] but not the configuration [ [PRES V] PAST $b e$ ]. I leave this issue open for future research.

John told me fifteen days ago that Julia is pregnant / \# is sleeping.

(76) J. adivinó hace 15 días la mujer que está embarazada / \# está durmiendo. $\mathrm{J}$. guessed since 15 days the woman that is pregnant /\# is sleeping 'Juan guessed two weeks ago which woman is pregnant / \# is sleeping.' 


\section{Endnotes}

1 Sharvit (2003) uses strategy I to illustrate the arguments in her paper.

2 There is a non-trivial problem in (37): it presupposes that there is a unique function of type $\langle\mathrm{s},\langle\mathrm{s}, \mathrm{e}\rangle\rangle$ whose value at the actual world $\mathrm{w}$ is the individual concept $<$ s,e $>$ known to Fred. But of course there are many such functions of type $<$ s, $<$ s,e $>>$. For the sake of the argument, I assume that this problem can be solved.

3 (64), (65) and (68) are modified from Sharvit (2003) in the order of arguments. (64)-(68) are further modified in that they now include world arguments.

\section{References}

Akmajian, A. 1970. On dedriving cleft sentences from pseudocleft sentences, Linguistic Inquiry 1, 140-168.

Enç, M. 1981. Tense without scope: an analysis of nouns as indexicals. University of Wisconsin, Madison, dissertation.

Enç, M. 1986. Towards a referential analysis of temporal expressions, Linguistics and Philosophy 9: 405-426.

Farkas, D. 1993. Modal anchoring and NP scope, ms. UC Santa Cruz.

Halvorsen, P. K. 1978. The Syntax and Semantics of Cleft Constructions. Univ. of Texas, Austin, $\mathrm{Ph}$. D. dissertation

Heim, I. 1979. Concealed Questions, in R. Bäuerle, U. Egli and A. von Stechow (eds.), Semantics from different points of view, Berling: Springer. Pp. 51-60.

Heim, I. 1994. Interrogative Semantics and Karttunen's Semantics for know, in A. Mittwoch et al. (eds.) Proceedings of IATL. Jerusalem.

Higgins, R. 1979. The Pseudo-Cleft Construction in English. NY: Garland.

Jacobson, P. 1994. Binding connectivity in copular sentences, in Harvey, M. and L. Santelmann (eds.), Proceedings of SALT 4. CLC Publications.

Karttunen, L. 1977. Syntax and Semantics of Questions, Linguistics and Philosophy 1, 3-44.

Kusumoto, K. 1999. Tense in embedded contexts. UMass Ph. D. diss.

Moltmann, F. 1997. Intensional verbs and quantifiers, Natural Language Semantics 5, 1-52.

Musan, R. 1995. On the temporal interpretation of Noun Phrases. MIT PhD diss.

Ogihara, T. 1996. Tense, attitude and scope. Dordrecht: Kluwer.

Quer, J. 1998. Mood at the interface, Utrecht Institute of Linguistics OTS.

Romero, M. 2003. Concealed questions and specificational subjects, Penn ms., submitted to Linguistics and Philosophy.

Sharvit, Y. 2003. Tense and Identity in Copular Constructions, Natural Language Semantics 11, 363-393.

Zimmermann, E. 1992. On the proper treatment of opacity in certain verbs, Natural Language Semantics 1, 149-180. 